\title{
Chondrocyte-Specific Regulatory Activity of Runx2 Is Essential for Survival and Skeletal Development
}

\author{
Haiyan Chen ${ }^{a}$ Farah Y. Ghori-Javed ${ }^{a}$ Harunur Rashid ${ }^{a}$ Rosa Serra ${ }^{b}$ \\ Soraya E. Gutierrez ${ }^{\mathrm{c}}$ Amjad Javed $^{\mathrm{a}}$

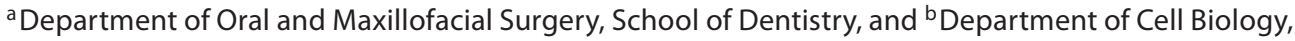 \\ University of Alabama at Birmingham, Birmingham, Ala., USA; ' Departamento de Biología Molecular, \\ Universidad de Concepción, Concepción, Chile
}

\section{Key Words}

Runx2 $\cdot$ Chondrocyte differentiation $\cdot$ Skeletal

development $\cdot$ Growth plate $\cdot$ Cartilage
Runx2 in chondrocytes is essential for endochondral ossification, and it is independent of the role of Runx2 in osteoblasts.

Copyright $\odot 2011$ S. Karger AG, Base

\begin{abstract}
Coordinated activities of multiple mesenchymal cell types contribute to the development of the mammalian skeleton formed through endochondral ossification. Synthesis of a cartilage template by chondrocytes is an obligatory step for the generation of skeletal elements during endochondral ossification. Gene ablation studies have established that Run $\times 2$ is an essential transcription factor for bone formation and the differentiation of skeletal cells. However, global gene deletion has failed to discern the tissue- and cell typespecific roles of Runx2. We generated floxed mice to elucidate the Runx 2 regulatory control distinctive to cartilage tissue during bone development. Exon 8 of the Runx 2 gene was selectively deleted in developing chondrocytes by utilizing Col2a-Cre mice. Cell- and tissue-specific gene recombination was confirmed by $\beta$-gal activity in R26R mice. The chondrocyte-specific loss of Runx2 caused failure of endochondral ossification, impaired craniofacial development, dwarfism, and perinatal lethality. Radiographic imaging and histochemical approaches were used to characterize the skeletal phenotype. We conclude that regulatory control of
\end{abstract}

\section{Introduction}

The mammalian skeleton is formed through intramembranous and endochondral ossification. In both bone formations, mesenchymal cells condense and differentiate into either osteoblasts or chondrocytes that

\begin{tabular}{ll} 
Abbreviations used in this paper \\
\hline Col2a1 & collagen type 2a \\
X-gal & 5-bromo-4-chloro-3-indolyl-beta-D-galactopyranoside \\
$\beta$-gal & $\beta$-galactosidase \\
Runx2 & runt-related transcription factor 2 \\
MMP13 & matrix metalloproteinase 13 \\
Sox9 & SRY (sex-determining region Y)-box 9 \\
Sox5 & SRY-box5 \\
Sox6 & SRY-box6 \\
PTH & parathyroid hormone \\
PTHrP & parathyroid hormone-related protein
\end{tabular}

\section{KARGER}

๑ 2011 S. Karger AG, Basel

Fax +4161306 1234

E-Mail karger@karger.ch

www.karger.com
Accessible online at: www.karger.com/cto
Dr. Amjad Javed

Department of Oral and Maxillofacial Surgery

School of Dentistry SDB 714, University of Alabama at Birmingham

1530 3rd Ave South, Birmingham, AL 35294-0007 (USA)

Tel. +1 205996 5124, E-Mail javeda@ uab.edu 
further progress through a number of maturational stages characterized by the induction of phenotypic marker genes [Stein et al., 1996; Mundlos et al., 1997; Olsen et al., 2000; Beck et al., 2001; Karsenty, 2001; Provot and Shipani, 2005; Wuelling and Vortkamp, 2010]. Runx2 and Osterix are considered master transcriptional regulators of osteoblast differentiation [Komori et al., 1997; Otto et al., 1997; Sato et al., 1998; Choi et al., 2001; Hess et al., 2001; Nakashima et al., 2002]. On the other hand, the Sox trio (Sox9, Sox5, and Sox6) are the main transcription factors triggering mesenchymal condensation to initiate chondrocyte differentiation [Lefebvre et al., 1998; Bi et al., 1999; Smits et al., 2001]. Runx2 knockin and knockout mice display a complete lack of both endochondral and intramembranous ossification, and they show an absence of chondrocyte and osteoblast differentiation [Komori et al., 1997; Otto et al., 1997; Choi et al., 2001; Fujita et al., 2004; Hinoi et al., 2006]. However, skeletogenesis is a highly complex process and requires the coordinated activity of multiple cell types including chondrocytes and osteoblasts. Runx2 global deletion and overexpression at nonphysiological levels limits options for identifying a cell- and tissue-specific contribution of Runx2.

To circumvent this problem and elucidate the Runx 2 regulatory control distinctive to cartilage tissue during bone development, we generated Runx2 floxed mice. Using biochemical and genetic approaches, we found that selective deletion of Runx 2 in chondrocytes results in failed endochondral ossification, dwarfism, and perinatal lethality.

\section{Materials and Methods}

\section{Generation of Runx2 Conditional Knockout Mice}

Exon 8 of the Runx 2 gene was floxed by inserting 2 directional Lox-p sites. Lox-p sequences were inserted first in intron 7 and second in exon 8 , immediately after the translational stop codon. Mouse embryonic stem cells with the correct homologous recombination were identified by Southern blot analysis and used for the production of chimeric mice. Germ line transmission and the establishment of Runx 2 floxed mice (Runx $2^{\mathrm{F} / \mathrm{F}}$ ) was confirmed by allele-specific genotyping and diagnostic restriction analysis of PCR products. Runx $2^{\mathrm{F} / \mathrm{F}}$ mice were crossed with collagen type $2 \mathrm{a}$ (Col2a1)-Cre mice [Ovchinnikov et al., 2000] to generate Run $2^{\Delta \mathrm{E} 8 /+\mathrm{Col} 2 \mathrm{a} 1}$ mice, and their progeny were intercrossed to obtain Runx $2^{\Delta \mathrm{E} 8 / \Delta \mathrm{E} 8 \mathrm{Col} 2 \mathrm{al}}, \mathrm{Runx}^{\Delta \mathrm{E} 8 /+\mathrm{Col} 2 \mathrm{a} 1}$, and Runx $2^{\mathrm{F} / \mathrm{F}}$ mice. All genotypes were determined using differential PCR. We maintained all mice under a 12-hour light:dark cycle with ad libitum access to regular food and water. All animal experiments were performed with the approval of the Animal Research Program of the University of Alabama at Birmingham and conformed to relevant guidelines and laws.
Determination of Chondrocyte Cell-Specific Cre Activity

For the assessment of tissue and cell type expression of Cre recombinase, the R26R line was utilized [Soriano, 1999]. Deskinned long bones of newborn mice were fixed in $10 \%$ phosphate-buffered formalin overnight at $4^{\circ} \mathrm{C}$ with gentle rotation and rinsed 4 times for $30 \mathrm{~min}$ each with $0.1 \mathrm{M}$ phosphate buffer $(\mathrm{pH}$ 7.3). Samples were then stained in freshly prepared 5-bromo4-chloro-3-indolyl-beta-D-galactopyranoside (X-gal) reaction buffer ( $5 \mathrm{~mm}$ potassium ferricyanide and ferrocyanide, $2 \mathrm{~mm}$ magnesium chloride, $0.2 \%$ NP40, $0.1 \%$ sodium deoxycholate, and $1 \mathrm{mg} / \mathrm{ml} \mathrm{X}$-gal) for $16 \mathrm{~h}$ at room temperature. Stained embryos were rinsed 4 times in $0.1 \mathrm{M}$ phosphate buffer for $30 \mathrm{~min}$ each before imaging. For histological analysis, X-gal-stained forelimbs were fixed in $10 \%$ phosphate-buffered formalin at $4^{\circ} \mathrm{C}$ overnight and dehydrated with serial ethanol solutions. Tissues were embedded in paraffin and sectioned at $7 \mu \mathrm{m}$; sections were counterstained with hematoxylin and counterstained with eosin.

\section{Radiographic Imaging and Histological Analysis}

For evaluation of the mineralized skeleton of new born mice, radiographic imaging was performed with a Faxitron (Faxitron $\mathrm{X}$-Ray Corporation) at a voltage of $22 \mathrm{mV}$ and an exposure time of $16 \mathrm{~s}$ to enhance soft tissue penetration. To understand the cellular defects in the long bones of Runx 2 conditional null mice, histological analyses were carried out as follows. Embryos were deskinned, eviscerated, and fixed in $4 \%$ paraformaldehyde (Sigma-Aldrich, St. Louis, Mo., USA) for 12 h. Specimens were dehydrated in ethanol gradient solution and embedded in paraffin. Tibia and femur sections were cut at a thickness of $7 \mu \mathrm{m}$ and mounted on Superfrost Plus slides. Sections were dewaxed in xylene and rehydrated in 100, 95, and 70\% ethanol and water. To analyze the general tissue morphology, hematoxylin and eosin staining was performed. Digital images were captured at a $10 \times$ magnification with a Nikon Eclipse 80i microscope.

\section{Results and Discussion}

\section{Runx2 Deletion in Chondrocytes Disrupts \\ Endochondral Ossification}

To direct Cre recombination events specifically in developing chondrocytes, we crossed our Runx2 floxed mice with transgenic mice carrying a Col2al-Cre gene. The Col2al promoter and enhancer fragment used can mimic the temporal and spatial expression of endogenous type II collagen [Ovchinnikov et al., 2000]. Homozygous mutants (Runx $2^{\Delta \mathrm{E} 8 / \Delta \mathrm{E} 8 \mathrm{Col} 2 \mathrm{a} 1}$ ) expired within minutes of birth due to respiratory failure, and they were significantly smaller in size and weight (data not shown). Radiographic imaging was performed initially to reveal the skeletal defect. Radiographs of wild-type littermates showed well-developed and mineralized skeletons (fig. 1a). Skeletal elements formed by endochondral ossification were absent (vertebra, pelvic, scapula, and metacarpal/metatarsal bones) or significantly short (ribs and 


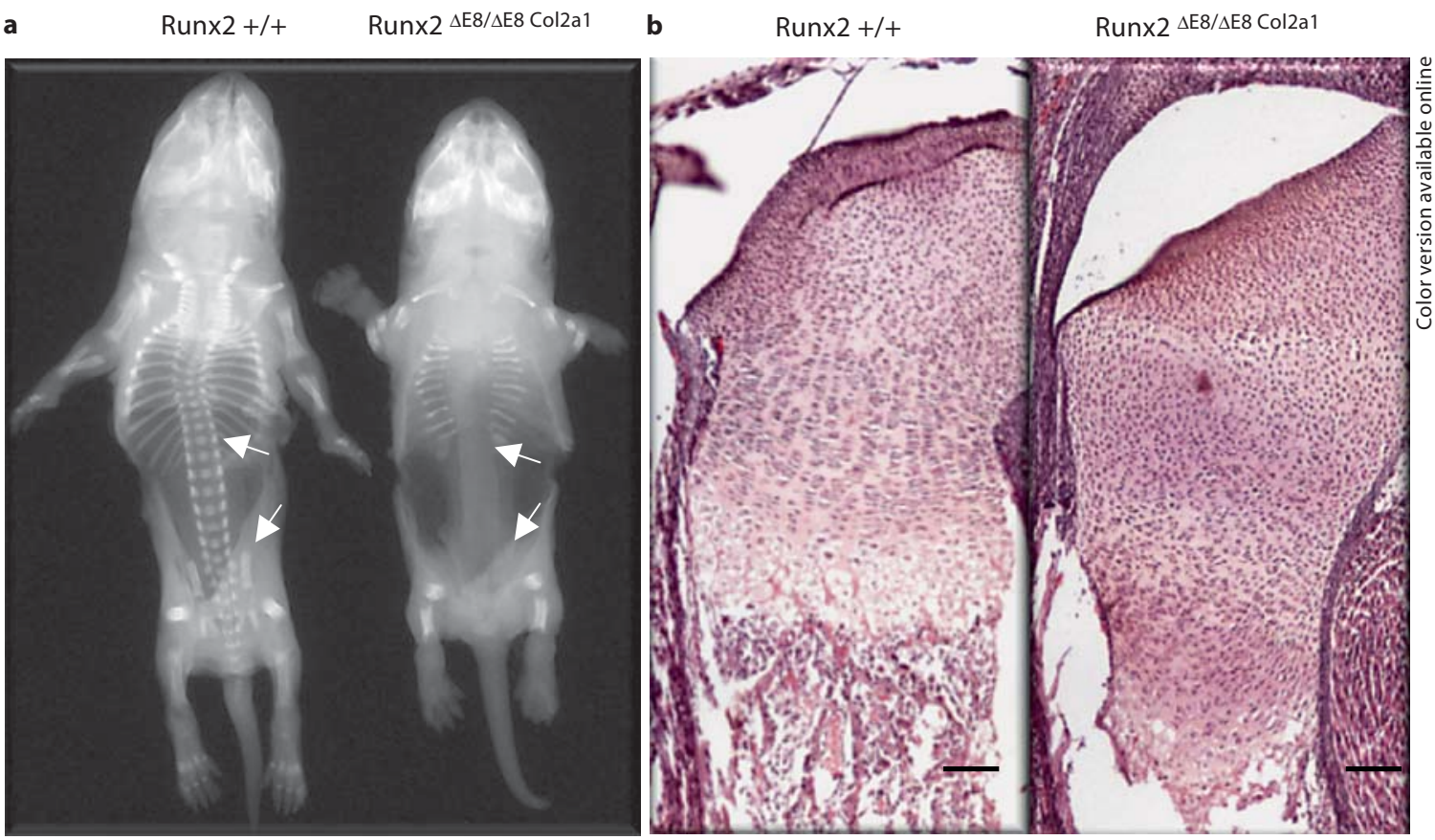

Fig. 1. Runx 2 activity in chondrocytes is essential for survival and endochondral ossification. a Whole-animal radiographic imaging of newborn littermates was processed simultaneously. Skeletal elements as seen in the dorsal view of newborn mice were evident in wild-type littermates. The homozygous mutant (Runx $2^{\Delta \mathrm{E} 8 / \Delta \mathrm{E} 8 \mathrm{Col} 2 \mathrm{al}}$ ) showed no vertebral column or pelvic bones (arrows) and only a residual signal in ribs and limb bones. b Embryonic femurs (E18) of the indicated genotype were fixed with $4 \%$ paraformaldehyde, processed, and embedded in paraffin. Serial sections were cut at $7 \mu \mathrm{m}$ and stained with hematoxylin and eosin. Images were captured with a Nikon Eclipse $80 \mathrm{i} \mathrm{micro-}$ scope at a $10 \times$ magnification. Multiple images from each section were stitched digitally, and an assembled picture is presented. Scale bar $=100 \mu \mathrm{m}$. limb bones) in homozygous mutants. Moreover, some craniofacial elements were undetectable or poorly developed. These data indicated a failed progression of endochondral ossification in the chondrocyte-specific Runx2 homozygous mutants. To better understand the cellular phenotype, we carried out a histological analysis on the femurs of littermates at E18.0. Wild-type femurs showed progression of well-shaped growth plates into different zones of chondrocyte maturation that changed over to calcified cartilage and a well-expanded ossified zone and also contained marrow cavities. These features of the growth plate were completely absent in homozygous mutants (fig. 1b). Absence of hypertrophic chondrocytes in the homozygous mutant femurs suggested that the reduction in limb length was coupled with inhibition of chondrocyte terminal maturation. Furthermore, in wild-type mice, the extracellular matrix surrounding hypertrophic chondrocytes was permissive to vascular invasion, with well-defined ingression of the skeletal cells of osteoblast lineage, the presence of red blood cells, and marrow cav- ities. However, we did not observe vasculature or blood cells in the mid-diaphyseal region of the mutant limbs (fig. 1b). Thus, Runx2 activity in chondrocytes is necessary for the vascular ingrowth that precedes marrow cavity formation. Our findings of endochondral ossification failure are consistent with the global Runx 2 null phenotype and transgenic mice expressing the dominant negative form of Runx 2 in chondrocytes [Komori et al., 1997; Otto et al., 1997; Ueta et al., 2001]. We found that Runx2 expression in chondrocytes triggers the induction of target genes, which are considered markers of chondrocyte differentiation (Col2a1, Col10a1, and MMP13). These genes were absent or markedly reduced in mutant mice. Although the expression of Sox9 and parathyroid hormone/parathyroid hormone-related protein (PTH/ PTHrP) was normal in Runx2 mutant chondrocytes, the disrupted chondrogenesis was linked to a loss of Ihh expression. Taken together, the results of our study reveal for the first time a novel role of endogenous Runx2 in chondrocytes in bone development and survival. 
Fig. 2. a Runx 2 is specifically deleted in the resting chondrocyte. Newborn R26R mice with or without the Col2al Cre transgene were collected for histological analysis. Long bones were processed as described in Methods. $\beta$-Gal activity is observed only in the chondrocytes of R26R;Col2a1-Cre+ mice. Note the absence of X-gal staining in the periosteum and osteoblasts in R26R;Col2a1-Cre+ mice. The Runx2 gene was deleted in resting chondrocytes and all subsequent stages of chondrocyte differentiation. b Key defects noted in different zones of mutant mice. Scale bar $=50 \mu \mathrm{m}$. a

R26R;Col2a1-Cre-

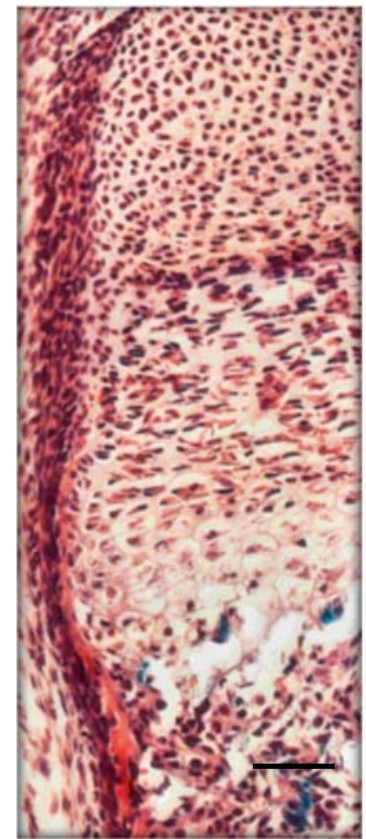

b

Defects in Runx $2^{\Delta \mathrm{E} 8 / \Delta \mathrm{E} 8 \mathrm{Col} 2 \mathrm{a} 1}$ bone

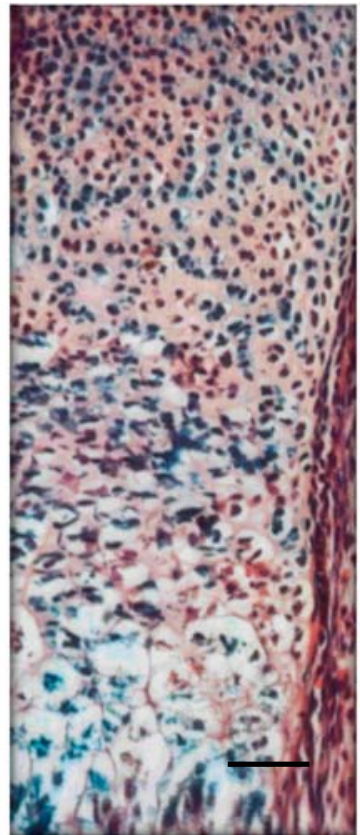

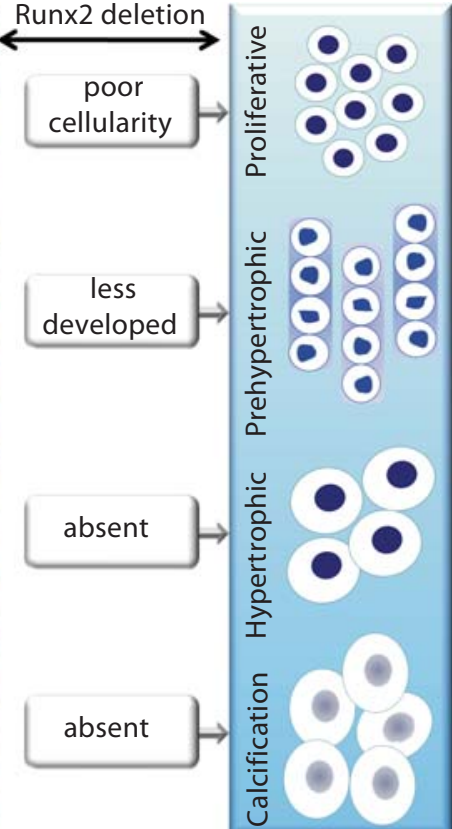

The Functional Integrity of Runx2 in Developing

Chondrocytes Is Essential for the Progression of

Chondrocyte Differentiation

Though Runx 2 is highly expressed in osteoblasts, it is also detected in chondrocytes [Komori et al., 1997; Otto et al., 1997]. During embryonic development, Runx2 is first detected in the notochord on E9.5, and by E12.5 it is highly expressed in the mesenchymal cells surrounding the cartilaginous condensation of the skeleton. During chondrogenesis, Runx2 expression is progressively increased, with the highest levels noted in terminal hypertrophic chondrocytes [Otto et al., 1997; Inada et al., 1999].

To better distinguish whether Runx 2 activity in chondrocytes is independent of the Runx 2 role in osteoblasts, we selectively deleted the Runx2 gene in chondrocytes. Chondrocyte-specific gene loss was first confirmed by analyzing the long bones for expression and activity of Cre-recombinase. Col2a1-Cre mice were crossed with R26R reporter mice to obtain Col2a1-Cre/R26R compound heterozygotes. Longitudinal sections of X-galstained bones showed high $\beta$-galactosidase $(\beta$-gal) activity in the proliferating chondrocytes of epiphysis (fig. 2). No $\beta$-gal activity was detected in osteoblast and perichondrial mesenchymal cells (fig. 2). These data provide assurance that the skeletal phenotype in these mice is due to a specific deletion of Runx 2 in chondrocytes, and it is independent of osteoblast activity. It is important to note that Cre-mediated gene recombination is an irreversible and permanent event. Thus, removal of Runx 2 in resting chondrocytes will historically mark the cells (arrow in fig. 2). If these cells manage to proceed through differentiation, Runx2 will be absent at all subsequent stages of maturation (fig. 2). Consistent with this, X-gal-stained positive cells were noted at all stages of chondrocyte differentiation. Consequently, we observed defects at all stages of chondrogenesis (fig. 2). Future studies will establish whether Runx 2 activity in hypertrophic chondrocyte is dependent on Runx2 function in proliferating chondrocytes by a hypertrophy stage-specific ablation of Runx2.

In summary, we demonstrated that a chondrocytespecific loss of Runx 2 causes lethality, failure of chondrocyte differentiation, and endochondral ossification.

\section{Acknowledgment}

This work was supported the National Institutes of Health (grant RO1 AG030228). 


\section{References}

Beck, G.R. Jr., B. Zerler, E. Moran (2001) Gene array analysis of osteoblast differentiation. Cell Growth Differ 12: 61-83.

Bi, W., J.M. Deng, Z. Zhang, R.R. Behringer, B. de Crombrugghe (1999) Sox9 is required for cartilage formation. Nat Genet 22: 85-89.

Choi, J.Y., J. Pratap, A. Javed, S.K. Zaidi, L. Xing, E. Balint, S. Dalamangas, B. Boyce, A.J. van Wijnen, J.B. Lian, J.L. Stein, S.N. Jones, G.S. Stein (2001) Subnuclear targeting of Runx/ Cbfa/AML factors is essential for tissue-specific differentiation during embryonic development. Proc Natl Acad Sci USA 98: 86508655.

Fujita, T., Y. Azuma, R. Fukuyama, Y. Hattori, C. Yoshida, M. Koida, K. Ogita, T. Komori (2004) Runx2 induces osteoblast and chondrocyte differentiation and enhances their migration by coupling with PI3K-Akt signaling. J Cell Biol 166: 85-95.

Hess, J., D. Porte, C. Munz, P. Angel (2001) AP-1 and $\mathrm{Cbfa} /$ runt physically interact and regulate parathyroid hormone-dependent MMP13 expression in osteoblasts through a new osteoblast-specific element 2/AP-1 composite element. J Biol Chem 276: 2002920038.

Hinoi, E., P. Bialek, Y.T. Chen, M.T. Rached, Y. Groner, R.R. Behringer, D.M. Ornitz, G. Karsenty (2006) Runx2 inhibits chondrocyte proliferation and hypertrophy through its expression in the perichondrium. Genes Dev 20: 2937-2942.

Inada, M., T. Yasui, S. Nomura, S. Miyake, K. Deguchi, M. Himeno, M. Sato, H. Yamagiwa, T. Kimura, N. Yasui, T. Ochi, N. Endo, Y. Kitamura, T. Kishimoto, T. Komori (1999) Maturational disturbance of chondrocytes in Cbfal-deficient mice. Dev Dyn 214: 279290.

Karsenty, G. (2001) Minireview: transcriptional control of osteoblast differentiation. Endocrinology 142: 2731-2733.
Komori, T., H. Yagi, S. Nomura, A. Yamaguchi, K. Sasaki, K. Deguchi, Y. Shimizu, R.T. Bronson, Y.H. Gao, M. Inada, M. Sato, R. Okamoto, Y. Kitamura, S. Yoshiki, T. Kishomoto (1997) Targeted disruption of Cbfal results in a complete lack of bone formation owing to maturational arrest of osteoblasts. Cell 89: 755-764.

Lefebvre, V., P. Li, B. de Crombrugghe (1998) A new long form of Sox5 (L-Sox5), Sox6 and Sox 9 are coexpressed in chondrogenesis and cooperatively activate the type II collagen gene. EMBO J 17: 5718-5833.

Mundlos, S., F. Otto, C. Mundlos, J.B. Mulliken, A.S. Aylsworth, S. Albright, D. Lindhout, W.G. Cole, W. Henn, J.H. Knoll, M.J. Owen, R. Mertelsmann, B.U. Zabel, B.R. Olsen (1997) Mutations involving the transcription factor CBFA1 cause cleidocranial dysplasia. Cell 89: 773-779.

Nakashima, K., X. Zhou, G. Kunkel, Z. Zhang, J.M. Deng, R.R. Behringer, B. de Crombrugghe (2002) The novel zinc finger-containing transcription factor osterix is required for osteoblast differentiation and bone formation. Cell 108: 17-29.

Olsen, B.R., A.M. Reginato, W. Wang (2000) Bone development. Annu Rev Cell Dev Biol 16: 191-220.

Otto, F., A.P. Thornell, T. Crompton, A. Denzel, K.C. Gilmour, I.R. Roswell, G.W. Stamp, R.S. Beddington, S. Muddlos, B.R. Olsen, P.B. Selby, M.J. Owen (1997) Cbfa1, a candidate gene for cleidocranial dysplasia syndrome, is essential for osteoblast differentiation and bone development. Cell 89: 765-771.

Ovchinnikov, D.A., J.M. Deng, G. Ogunrinu, R.R. Behringer (2000) Col2a1-directed expression of Cre recombinase in differentiating chondrocytes in transgenic mice. Genesis 26: 145-146.

Provot, S., E. Schipani (2005) Molecular mechanisms of endochondral bone development. Biochem Biophys Res Commun 328: 658665 .
Sato, M., E. Morii, T. Komori, H. Kawahata, M. Sugimoto, K. Terai, H. Shimizu, T. Yasui, H. Ogihara, N. Yasui, T. Ochi, Y. Kitamura, Y. Ito, S. Nomura (1998) Transcriptional regulation of osteopontin gene in vivo by PEBP2alphaA/CBFA1 and ETS1 in the skeletal tissues. Oncogene 17: 1517-1525.

Smits, P., P. Li, J. Mandel, Z. Zhang, J.M. Deng, R.R. Behringer, B. de Crombrugghe, V. Lefebvre (2001) The transcription factors L-Sox 5 and Sox6 are essential for cartilage formation. Dev Cell 1: 277-290.

Soriano, P. (1999) Generalized lacZ expression with the ROSA26 Cre reporter strain. Nat Genet 21: 70-71.

Stein, G.S., J.B. Lian, J.L. Stein, A.J. van Wijnen, M. Montecino (1996) Transcriptional control of osteoblast growth and differentiation. Physiol Rev 76: 593-629.

Ueta, C., M. Iwamoto, N. Kanatani, C. Yoshida, Y. Liu, M. Enomoto-Iwamoto, T. Ohmori, H. Enomoto, K. Nakata, K. Takada, K. Kurisu, T. Komori (2001) Skeletal malformations caused by overexpression of Cbfal or its dominant negative form in chondrocytes. J Cell Biol 153: 87-100.

Wuelling, M., A. Vortkamp (2010) Transcriptional networks controlling chondrocyte proliferation and differentiation during endochondral ossification. Pediatr Nephrol 25: 625-631.

Yoshida, C.A., H. Yamamoto, T. Fujita, T. Furuichi, K. Ito, K. Inoue, K. Yamana, A. Zanma, K. Takada, Y. Ito, T. Komori (2004) Runx 2 and Runx 3 are essential for chondrocyte maturation, and Runx 2 regulates limb growth through induction of Indian hedgehog. Genes Dev 18: 952-963.

Zheng, Q., G. Zhou, R. Morello, Y. Chen, X. Garcia-Rojas, B. Lee (2003) Type X collagen gene regulation by Runx 2 contributes directly to its hypertrophic chondrocyte-specific expression in vivo. J Cell Biol 162: 833-842. 